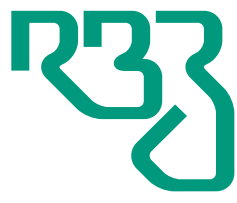

Revista

Brasileira de

Zootecnia

Brazilian Journal of Animal Science

ISSN 1806-9290

www.rbz.org.br

\section{Mycotoxin contamination of diets for beef cattle finishing in feedlot}

\author{
Letícia Custódio $^{1}$ (iD, Laura Franco Prados ${ }^{2 *}$ iD , Alexandros Yiannikouris ${ }^{3}$ iD, \\ Vaughn Holder ${ }^{4}$ iD, James Pettigrew ${ }^{5}$ iD, Leandro Kuritza ${ }^{6}$ iD, Flávio \\ Dutra de Resende $^{1,2}$ (iD, Gustavo Rezende Siqueira ${ }^{1,2}$ (iD \\ ${ }^{1}$ Universidade Estadual Paulista, Departamento de Zootecnia, Jaboticabal, SP, Brasil. \\ ${ }^{2}$ Agência Paulista de Tecnologia dos Agronegócios, Colina, SP, Brasil. \\ ${ }^{3}$ Center for Animal Nutrigenomics and Applied Animal Nutrition, Alltech, Nicholasville, USA. \\ ${ }^{4}$ Alltech Inc, Nicholasville, USA. \\ ${ }^{5}$ Pettigrew Research Services, Inc., Champaign, IL, USA. \\ ${ }^{6}$ Alltech do Brasil, Araucária, PR, Brasil.
}

\begin{abstract}
The objective of this survey was to identify what mycotoxins were present in ingredients used in diets offered to beef cattle in feedlots and their concentrations. The survey covered 30 Brazilian feedlots located in the five major beef-producing states. Samples of total mixed ration (TMR) and ingredients were collected and analyzed for mycotoxin using ultra-performance liquid chromatography coupled to tandem mass spectrometry. Mycotoxin concentrations were further interpreted according to known species-specific sensitivities and normalized according to the principles of toxic equivalent factors (risk equivalent quantities - REQ) expressed in $\mu \mathrm{g} \mathrm{kg}{ }^{-1}$ of aflatoxin B1-equivalent. Forty percent of the visited feedlots had apparent fungi in TMR. However, only one feedlot (3\%) used a mycotoxin adsorbent. On the other hand, diets with high contamination presented no apparent fungi. One hundred percent of TMR was contaminated. All samples presented at least one mycotoxin contamination, with $65.5 \%$ considered low contamination, $27.6 \%$ medium contamination, and $6.90 \%$ high contamination. The toxins identified in TMR were fumonisins (most frequently), trichothecenes $\mathrm{A}$, trichothecenes $\mathrm{B}$, fusaric acid, aflatoxins, and ergot (mean concentration values: 2,330, 104.3, 79.5, 105, 10.5, and $5.5 \mu \mathrm{g} \mathrm{kg}^{-1}$, respectively). According to the contamination of TMR samples per region, Mato Grosso do Sul state presented the highest contaminations. Peanut meal was the most contaminated ingredient. One hundred percent of TMR in Brazilian feedlot is contaminated. Fumonisins were the mycotoxin most frequent and at highest concentrations in TMR samples. Moreover, mycotoxin concentrations have a distinct pattern among ingredients, TMR, and feedlots (local).
\end{abstract}

Keywords: aflatoxin, beef cattle, feedlots, fumonisin, ingredients

\title{
Introduction
}

Mycotoxin contamination occurs in many materials, including animal feed, animal products, and soil. As these toxins affect animal production and health, they can cause substantial economic losses. Factors that can affect the production of mycotoxin by fungi include abiotic factors, such as temperature and humidity, and biotic factors, such as fungal load at the time of transportation and storage. Besides, there are two types of fungi, those that act before harvest, commonly called field fungi, and those that occur only after harvest, called storage fungi (Tola and Kebede, 2016). 
The most important genus of mycotoxigenic fungi are Aspergillus, Alternaria, Claviceps, Fusarium, Penicillium, and Stachybotrys (Milićević et al., 2010), while the common mycotoxins investigated and found in ingredients of animal diets worldwide are: aflatoxin, fumonisin, zearalenone, ochratoxin, and trichothecenes (Chaytor et al., 2011). However, as the presence of these mycotoxins relates to specific environmental conditions and type of material, the characteristics of contamination could vary regionally. Nevertheless, the trading of ingredients among regions, countries, and continents could also play a role in the contamination dynamics and change mycotoxins distribution patterns.

Thus, the objectives of this survey were to identify the mycotoxins and their concentrations in ingredients used in typical total mixed rations (TMR) used in Brazilian beef feedlots and relate these results to characteristics of the feedlot.

\section{Material and Methods}

The survey was developed in the years 2015/2016. Thirty Brazilian feedlots located in five different Brazilian states (Mato Grosso [MT], Mato Grosso do Sul [MS], Goiás [GO], Minas Gerais [MG], and São Paulo [SP]) were used in the survey (Table 1). These states are the five major beef-producing states, responsible for $81.3 \%$ of all animals finished in feedlots in Brazil and, therefore, were chosen for the evaluation. Each feedlot was visited by the authors, where samples of ingredients and TMR were collected, and a questionnaire concerning aspects of the feedlot and its management was completed.

The questionnaire contained 61 questions that were categorized into the following topics: general information about the facilities (12 questions), general cattle management (21 questions), diets (18 questions), concentrates and co-products used (four questions), and roughage used (six questions).

Samples of TMR $(n=30)$ and ingredients were sent to the research facility (Colina, SP, BRA). These samples were lyophilized and ground in the laboratory. Subsequently, they were vacuum-packed and sent to the $37+{ }^{\circledR}$ Analytical Services Laboratory (Lexington, KY, USA) for mycotoxin analysis.

The evaluation of mycotoxins comprised two distinct steps. In a first step, the absolute quantification of 38 different mycotoxins was performed using a validated and ISO/IEC 17025:2005 accredited method by means of ultra-performance liquid chromatography (UPLC) electrospray ionization tandem mass spectrometry (ESI-MSMS), involving an isotopic dilution step and a data normalization process. In a second step, mycotoxin concentrations were further interpreted according to known species-specific sensitivities and normalized according to the principles of toxic equivalent factors, determining the risk equivalent quantities (REQ) expressed in $\mu \mathrm{g} \mathrm{kg}^{-1}$ of AFB1- equivalent.

The ingredients of the ten most contaminated TMR samples $(n=41)$ were sent to the $37+{ }^{\circledR}$ Analytical Services Laboratory for analysis of mycotoxins to evaluate which ingredients were most responsible for TMR contamination.

The responses generated from the questionnaire and the analytical data were subjected to descriptive analysis using the UNIVARIATE procedure of SAS (Statistical Analysis System, version 9.4) and

Table 1 - Brazilian states visited and their number of animals in the feedlot

\begin{tabular}{lcc}
\hline Brazilian state & Number of animals ${ }^{1}$ & \% of total \\
\hline Mato Grosso & 977,131 & 24.4 \\
Goiás & 817,442 & 20.4 \\
Mato Grosso do Sul & 636,395 & 15.9 \\
São Paulo & 628,940 & 15.7 \\
Minas Gerais & 197,906 & 4.90 \\
Total & $4,008,764$ & 100 \\
\hline
\end{tabular}

${ }^{1}$ ANUALPEC (2015). 
multivariate statistics using STATISTICA (STATSOFT, Inc, Tulsa, OK, USA). The multivariate analyses were performed using cluster analysis, which allows grouping of the variables by the Ward method and considers the Euclidean distance for group establishment. Starting of the number of groups adopted in the cluster analysis by the hierarchical method, the grouping analysis was developed by a non-hierarchical method using the k-means algorithm, which complements the results of the previous analysis. Finally, through the analysis of principal components, it was possible to evaluate the importance of each component and the discriminatory power of each variable.

\section{Results}

Eighteen feedlots (60\%) had less than 5,000 animals, whereas seven (23\%) had from 5,000 to 10,000 animals, and five $(17 \%)$ had more than 10,000 animals on feeding. The observed average daily gain (ADG) ranged from 0.70 to $1.85 \mathrm{~kg}$ in these feedlots. However, most of the feedlots (63\%) had animals with a near-average ADG (1.53 $\mathrm{kg} \mathrm{day}^{-1}$; Table 2).

Most feedlots (83\%) stored the ingredients in a common barn, and $57 \%$ of the feedlots cleaned the storage barns (Table 3). Forty percent of the visited feedlots had apparent fungi in TMR. However, only one feedlot (3\%) used a mycotoxin adsorbent (Table 3). Besides, from twelve diets with apparent fungi, six showed moderate mycotoxin contamination, while six had low contamination. On the other hand, diets with high contamination (6.9\%) presented no apparent fungi.

Almost all TMR samples (93.3\%) presented fumonisin (B1+B2), 80\% of TMR samples had fusaric acid, and $66.7 \%$ had trichothecenes A (T-2, H-T2, diacetoxyscirpenol, and neosolaniol), while aflatoxin

Table 2 - General characteristics of the feedlots sampled

\begin{tabular}{|c|c|c|c|}
\hline Item & Mean & Minimum & Maximum \\
\hline Number of animals & 7,085 & 324 & 50,000 \\
\hline Average daily gain $\left(\mathrm{kg} \mathrm{day}^{-1}\right)$ & 1.53 & 0.70 & 1.85 \\
\hline Days on feed & 107 & 85 & 155 \\
\hline Feeding frequency (times day ${ }^{-1}$ ) & 5 & 3 & 8 \\
\hline
\end{tabular}

Table 3 - Type information of the feedlots visited

\begin{tabular}{lcc}
\hline Item & Number of responses & \% of responses \\
\hline Type of barn for feed storage & 25 & 83.3 \\
Common & 3 & 10.0 \\
Double side & 1 & 3.33 \\
Silo & 1 & 3.33 \\
No barn & & \\
Barn cleaning & 17 & 56.7 \\
Yes & 13 & 43.3 \\
No & & \\
Apparent fungi in total mixed ration & 12 & 40.0 \\
Yes & 18 & 60.0 \\
No & & 3.33 \\
Use of mycotoxin adsorbent? & 1 & 96.7 \\
$\quad$ Yes & 29 & \\
$\quad$ No & & \\
\hline
\end{tabular}


(B1+B2+G1+G2), trichothecenes B (DON, 15-acetyl DON, 3-acetyl DON, fusarenol X, nivalenol, and DON 3-glycoside), ergot, and other mycotoxins produced by Penicillium (patulin, penicillic acid, roquefortine C, mycophenolic acid, and wortmannin) were present in fewer samples $(6.67,20.0,33.3$, and 6.67, respectively). Ochratoxin A, zearalenone, and other mycotoxins produced by Aspergillus (gliotoxin, sterigmatocystin, verruculogen) were not found (Figure 1). Fumonisin was the mycotoxin with the highest level of contamination in the samples (Figure 2).

In this study, $65.5 \%$ of TMR samples were classified as low REQ $27.6 \%$ as intermediate REQ, and $6.9 \%$ as high REQ (Figure 3). The maximum REQ found in TMR used in the feedlots evaluated in this survey was $230 \mu \mathrm{g} \mathrm{kg}^{-1} \mathrm{AFB} 1$-equivalent, and the minimum REQ was $1 \mu \mathrm{g} \mathrm{kg}{ }^{-1} \mathrm{AFB} 1$-equivalent.

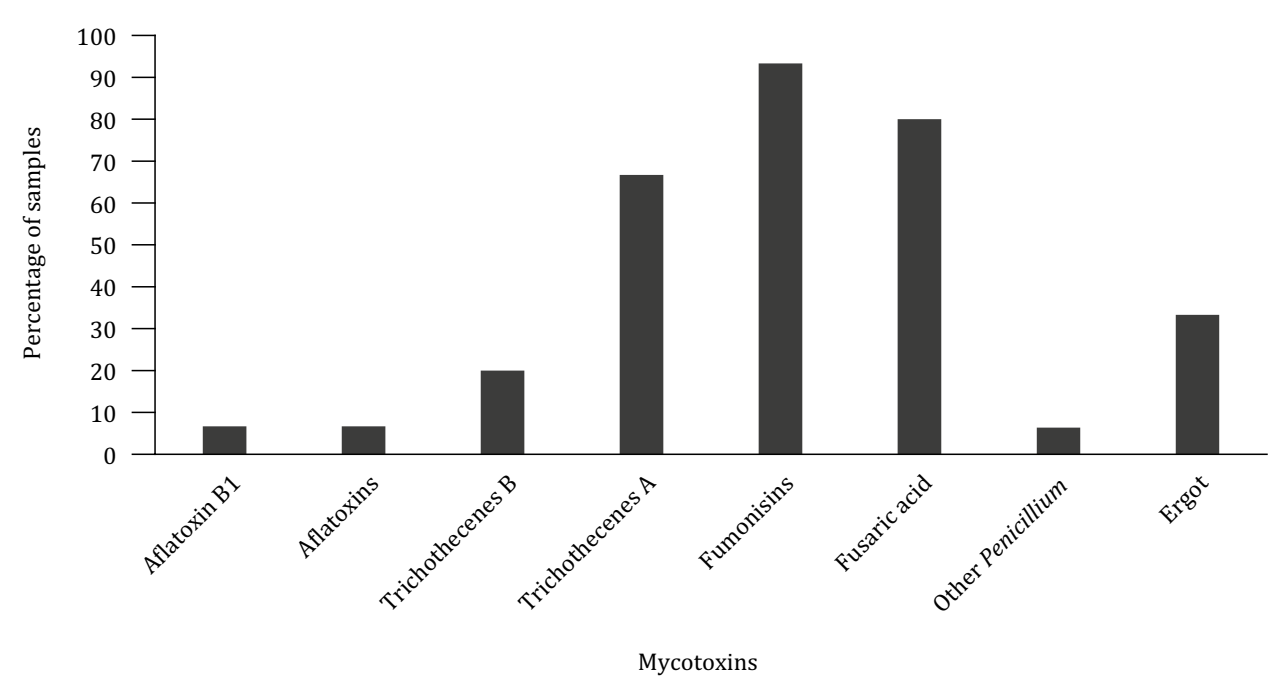

Aflatoxins = aflatoxin $\mathrm{B} 1+\mathrm{B} 2+\mathrm{G} 1+\mathrm{G} 2$; trichothecenes $\mathrm{B}=\mathrm{D} 0 \mathrm{~N}$; trichothecenes $\mathrm{A}=$ toxin $\mathrm{T}-2+\mathrm{HT}-2$; fumonisins = fumonisins $\mathrm{B} 1+\mathrm{B} 2$; other Penicillium = patulin, penicillic acid, roquefortine $\mathrm{C}$, mycophenolic acid, wortmannin.

Figure 1 - Mycotoxin occurrence (\%) of total mixed ration samples of 30 feedlots collected in five Brazilian states.

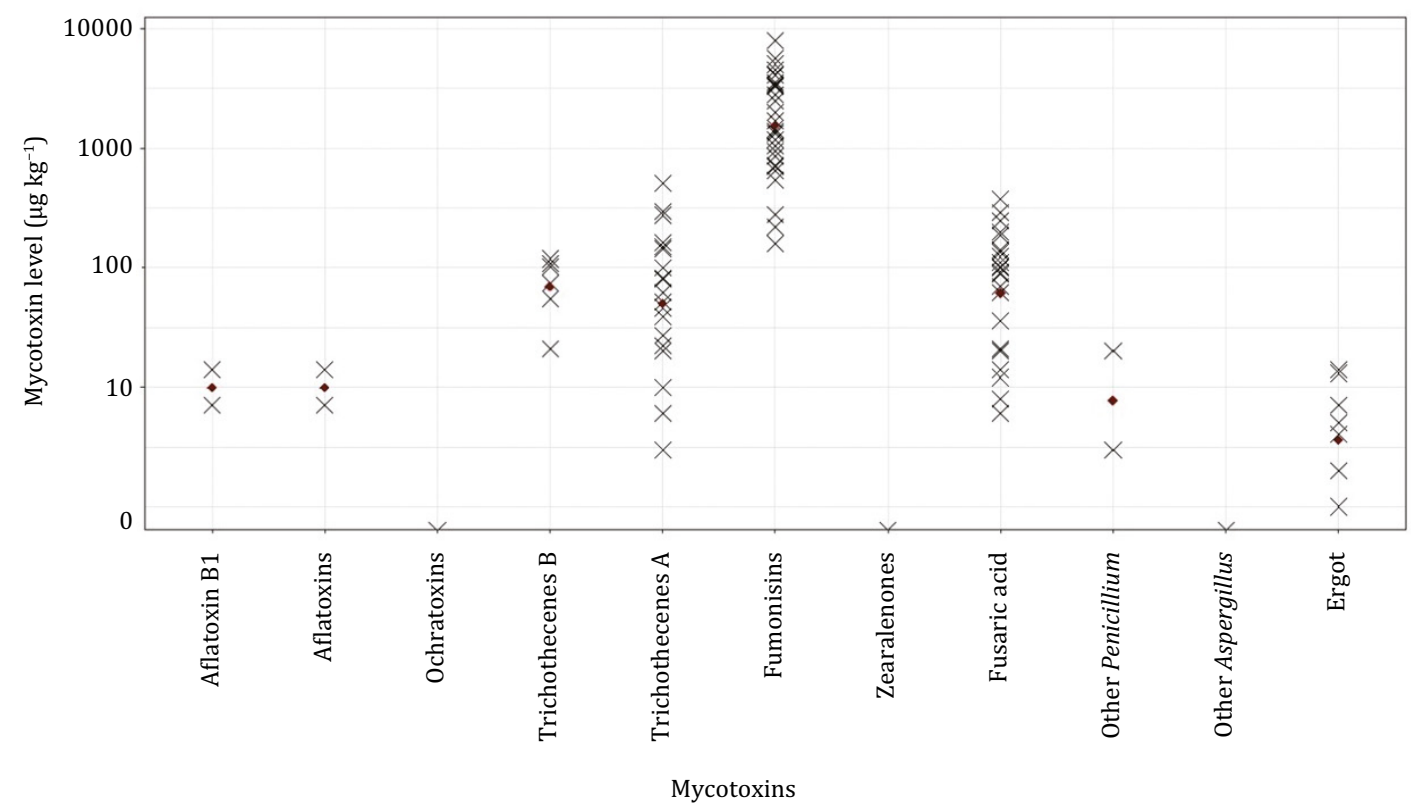

Aflatoxins = aflatoxin $\mathrm{B} 1+\mathrm{B} 2+\mathrm{G} 1+\mathrm{G} 2$; ochratoxin = OTA; trichothecenes B = DON; trichothecenes A = toxin T-2 + HT -2 ; fumonisins = fumonisins B1+B2; other Penicillium = patulin, penicillic acid, roquefortine C, mycophenolic acid, wortmannin; other Aspergillus = gliotoxin, sterigmatocystin, verruculogen.

Figure 2 - Mycotoxin concentration ( $\mu \mathrm{g} \mathrm{kg}^{-1}$ ) of total mixed ration samples of 30 feedlots collected in five Brazilian states. 
The analysis of principal components allowed the construction of two-dimensional biplot formed by the first two major components (Factor 1 and Factor 2; Figure 4). The samples contaminated with aflatoxins were separated from the other samples and the REQ. The REQ computes a multicontamination complex situation pertaining to feedstuffs into one single value (Yiannikouris, 2015). It is possible to observe that the combination of other mycotoxins can be more dangerous than aflatoxin by itself.

It can be observed, according to the contamination of the TMR samples per region, that Mato Grosso do Sul presented the highest contaminations in some of the TMR (above 200 ppb; Figure 5).

The ingredients from the ten most contaminated diets were analyzed to determine which of them were responsible for the high contamination and which mycotoxins were associated with each ingredient. The roughage source most often used in these feedlots was corn silage and the most common concentrate sources were corn and cottonseed (Table 4). The mean levels of contamination of ingredients from the ten most contaminated diets indicated which ingredients were most responsible for TMR contamination and which mycotoxin stood out in each source (Table 5).

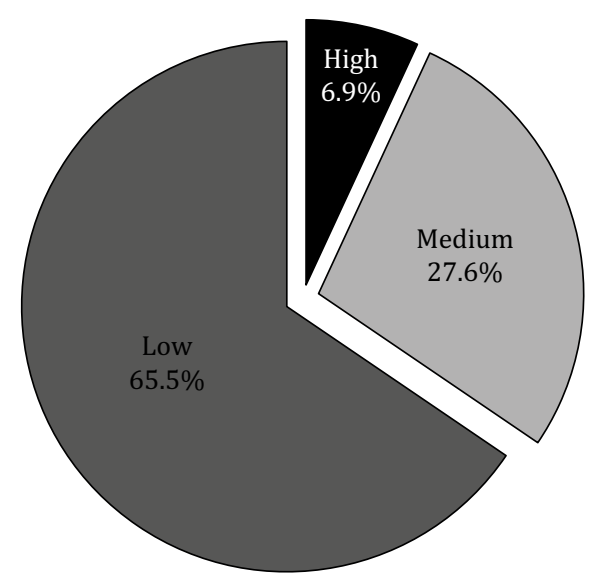

Figure 3 - Percentage of total mixed ration samples of 30 feedlots in five Brazilian states with low $\left(0-50 \mu \mathrm{kg}^{-1}\right)$, medium (51-100 $\mu \mathrm{g} \mathrm{kg}^{-1}$ ), and high (>100 $\mu \mathrm{g} \mathrm{kg}^{-1}$ ) risk equivalent quantity (REQ) to beef cattle.

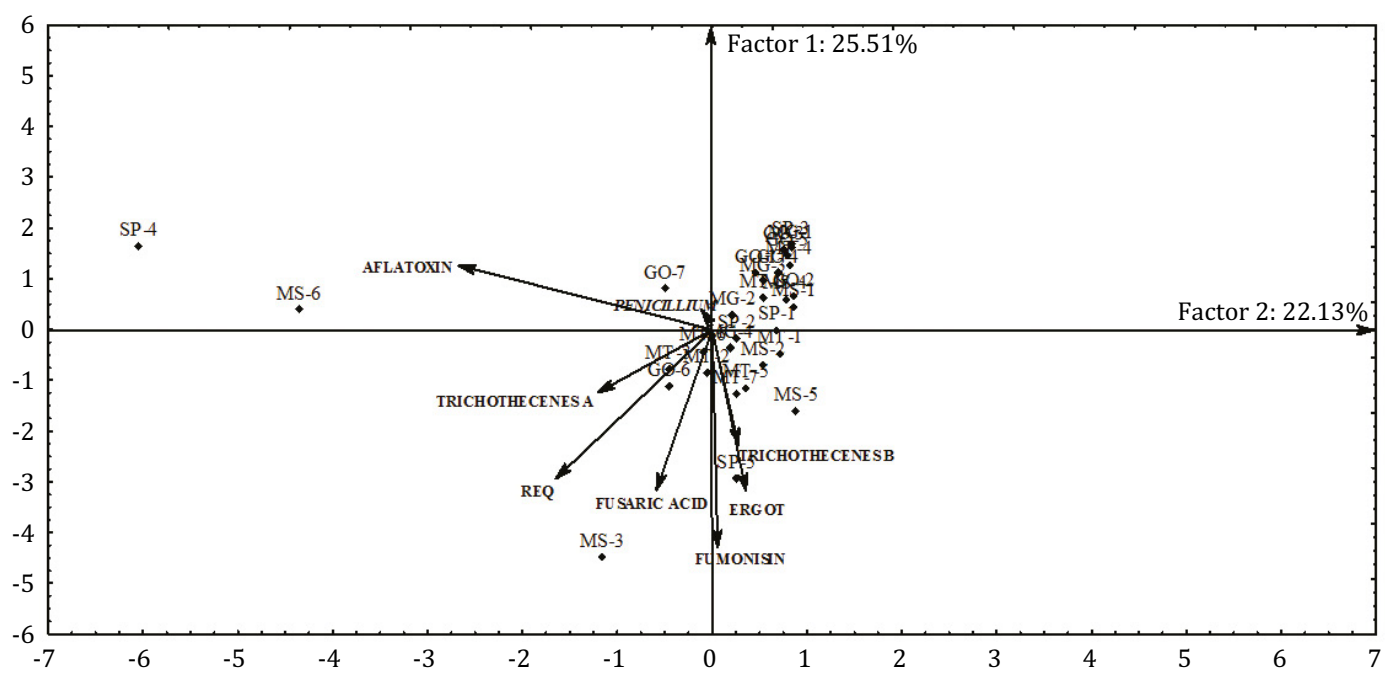

Figure 4 - Principal components of risk equivalent quantity (REQ) of total mixed ration samples of 30 feedlots collected in five Brazilian states. 


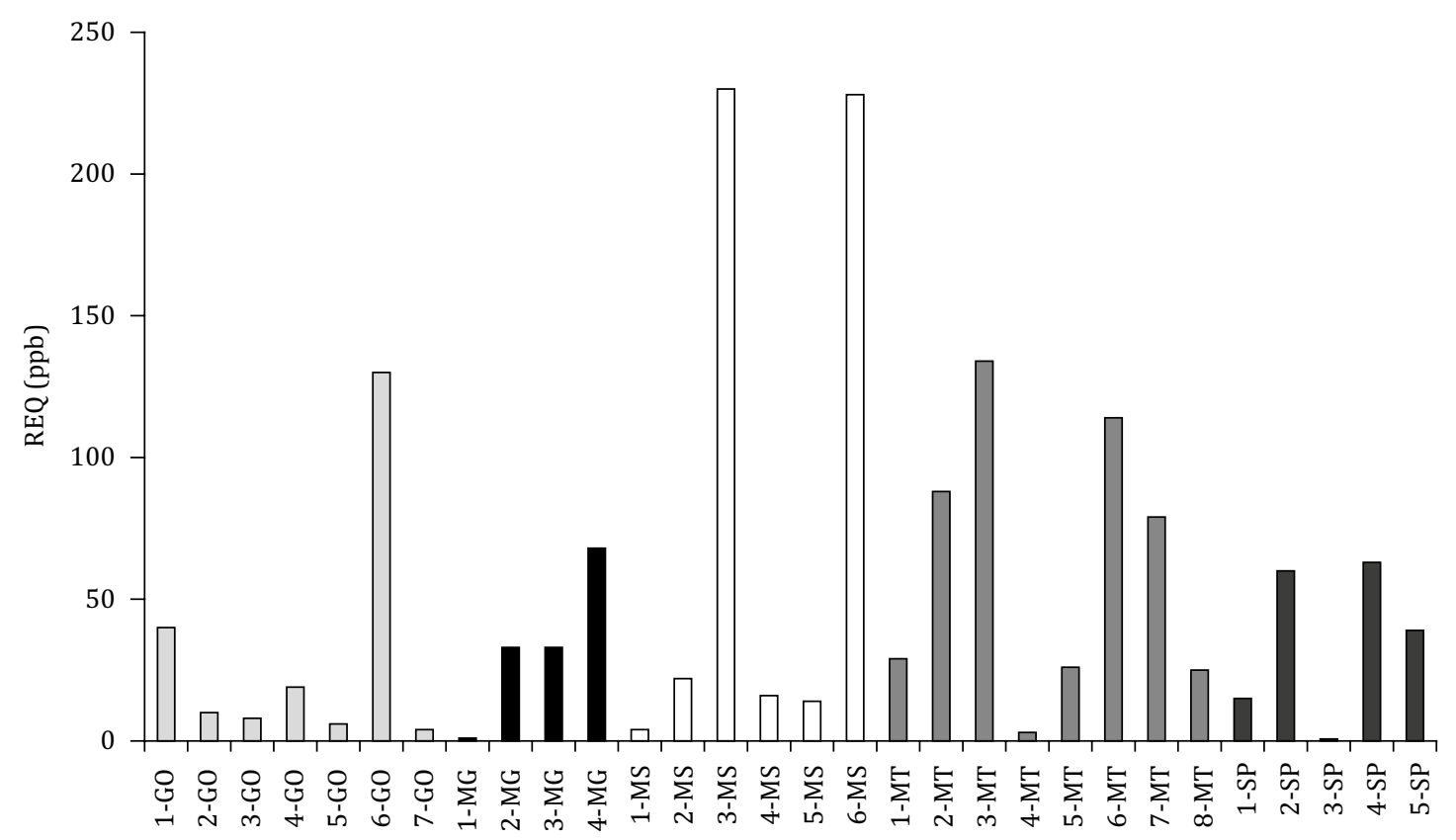

GO = Goiás; MG = Minas Gerais; MS = Mato Grosso do Sul; MT = Mato Grosso; SP = São Paulo.

Figure 5 - Contamination per state of total mixed ration samples of 30 feedlots in five Brazilian states.

Table 4 - Roughage and concentrate sources used in diets of feedlots visited

\begin{tabular}{lcc}
\hline Item & Number of responses & \% of responses \\
\hline Roughage source & & 43.3 \\
Corn silage & 13 & 6.67 \\
Corn residue & 2 & 6.67 \\
Grass silage & 2 & 6.67 \\
Sugarcane straw + Tifton hay & 2 & 36.7 \\
Others ${ }^{1}$ & 11 & \\
Concentrate source & & 76.7 \\
Corn & 23 & 53.3 \\
Cottonseed & 16 & 36.7 \\
Cottonseed cake & 11 & 23.3 \\
Citrus pulp & 7 & 23.3 \\
Soybean meal & 7 & 20.0 \\
Soybean hulls & 6 & 16.7 \\
Corn germ & 5 & 16.7 \\
High-moisture corn & 5 & 13.3 \\
Peanut meal & 5 & 13.3 \\
Sorghum & 4 & 10.0 \\
Refinazil & 4 & 10.0 \\
Soybean residue & 3 & 40.0 \\
Others & & \\
\hline
\end{tabular}

${ }^{1}$ Other roughages sources: 3.33\% each: Brachiaria hay, corn silage + ear corn silage, corn silage + grass silage, corn silage + sugarcane bagasse, cotton residue, ear corn silage + sugarcane bagasse, cotton residue, ear corn silage + sugarcane bagasse, grass, millet and sorghum silage, sorghum silage, sugarcane bagasse, sugarcane bagasse + Brachiaria hay, sugarcane silage.

2 Other concentrate sources: $3.33 \%$ each: dehydrated cottonseed, crambe meal, corn DDGS, microalgae, orange bagasse, peanut starch, rice meal, rice residue, rehydrated sorghum, sunflower cake, sunflower meal, tomato + corn residue. 
Table 5 - Mean mycotoxin contamination $\left(\mu \mathrm{g} \mathrm{kg}^{-1}\right)$ of ingredients of ten most contaminated total mixed ration (TMR)

\begin{tabular}{|c|c|c|c|c|c|c|c|c|c|c|c|c|}
\hline Item & No. & REQ & AFB1 & $\begin{array}{l}\text { Other } \\
\text { aflatoxins }\end{array}$ & $\begin{array}{l}\text { Tricho } \\
\text { B }\end{array}$ & $\begin{array}{c}\text { Tricho } \\
\text { A }\end{array}$ & Fumo & ZEA & $\begin{array}{c}\text { Fusaric } \\
\text { acid }\end{array}$ & Penic & Asper & Ergot \\
\hline \multicolumn{13}{|l|}{ Roughages } \\
\hline Corn silage & 1 & 50.0 & - & - & - & - & 7,116 & - & 619 & - & - & 22.0 \\
\hline Sugarcane bagasse & 2 & 6.00 & - & - & 25.0 & - & 1,774 & - & 13.0 & - & - & - \\
\hline Sugarcane straw & 1 & 134 & - & - & 2,276 & 21.0 & - & - & 87.0 & - & - & - \\
\hline Tifton hay & 1 & 12.5 & - & - & - & - & 270 & - & 25.5 & 13.0 & 1.50 & 0.50 \\
\hline \multicolumn{13}{|c|}{ Concentrates and byproducts } \\
\hline Citrus pulp & 4 & 14.0 & - & - & - & - & - & - & 88.3 & - & - & 125 \\
\hline Corn & 9 & 58.4 & - & - & 12.1 & 2,536 & 18,402 & 5.60 & 104 & - & - & - \\
\hline Corn germ & 1 & 103 & - & - & 613 & - & 25,801 & - & 152 & - & - & - \\
\hline Cottonseed cake & 2 & 21.0 & - & - & - & - & - & - & 409 & - & 0.50 & - \\
\hline Cottonseed & 3 & 4.67 & - & - & - & - & 1,042 & - & 39.7 & - & - & - \\
\hline Crambe meal & 1 & 6.00 & - & - & - & - & 1,192 & - & 54.0 & - & - & 2.00 \\
\hline Corn DDGS & 1 & 118 & 6.00 & 6.00 & 150 & - & 12,184 & 206 & 693 & 11.0 & - & 3.00 \\
\hline Peanut meal & 2 & 1,018 & 471 & 578 & - & - & - & - & 483 & - & 555 & - \\
\hline Peanut starch & 1 & 58.0 & - & - & - & - & 3,362 & - & 676 & - & 21.0 & - \\
\hline Refinazil & 1 & 277 & - & - & - & - & 48,828 & - & 2,347 & 30.0 & - & 201 \\
\hline Soybean hulls & 2 & 8.50 & - & - & - & 8.50 & 217 & - & 15.0 & - & 1.00 & - \\
\hline Soybean meal & 3 & 63.7 & - & - & - & 84.3 & 28.3 & - & 13.0 & - & - & 4.70 \\
\hline Soybean residue & 1 & 239 & - & - & - & 306 & 243 & - & - & - & - & 3.00 \\
\hline
\end{tabular}

DDGS - dried destillers grains with solubles; REQ - risk equivalent quantity; AFB1 = aflatoxin B1; other aflatoxins = B1+B2+G1+G2; tricho $\mathrm{B}=$ DON; tricho A = toxin T-2 + HT-2; fumonisins = fumonisins B1+B2; ZEA = zearalenone; penic = patulin, penicillic acid, roquefortine C, mycophenolic acid, wortmannin; asper = gliotoxin, sterigmatocystin, verruculogen.

The cluster analysis of all contaminated ingredients allowed the construction of a dendrogram resulting from hierarchical grouping analysis (Figure 6a) and non-hierarchical method (Figure 6b), characterizing three different groups by contamination level (Figure 6a), or according to the contamination levels and mycotoxin type (Figure 6b).

\section{Discussion}

Mycotoxins are an important issue because they can affect production cost and could also impact the health of both animals and humans (Aslam et al., 2016). This study assessed the types and quantity of mycotoxins present in diets of beef cattle in Brazilian feedlots. The diets in visited feedlots showed different levels of contamination, but $100 \%$ of TMR samples had some contamination. The type of mycotoxins varies largely by the type of diet component, but the level of contamination varies within the ingredient. For example, a sample of peanut meal and one of corn were extremely contaminated, while other samples of the same materials collected from other feedlots had low contamination, indicating the dependency of more than one factor.

The high prevalence of fumonisin, trichothecenes A, and fusaric acid in the samples can be attributed to the type of feedstuffs used in the analyzed diets. Species of Fusarium produce fumonisin, and these toxins occur very often in corn (Zhang and Caupert, 2012). In this survey, 76.7\% of the feedlots used corn, $43.4 \%$ used corn silage, $16.7 \%$ used corn germ, $10 \%$ used refinazil, and $3.33 \%$ used corn DDGS, consistent with the high frequency of fumonisin in TMR samples of this survey. More broadly, corn is the primary source of grain used in feedlot diets (Vasconcelos and Galyean, 2007; Millen et al., 2009); therefore, this toxin can be very important for cattle in feedlots, since the ingestion of highly 
A

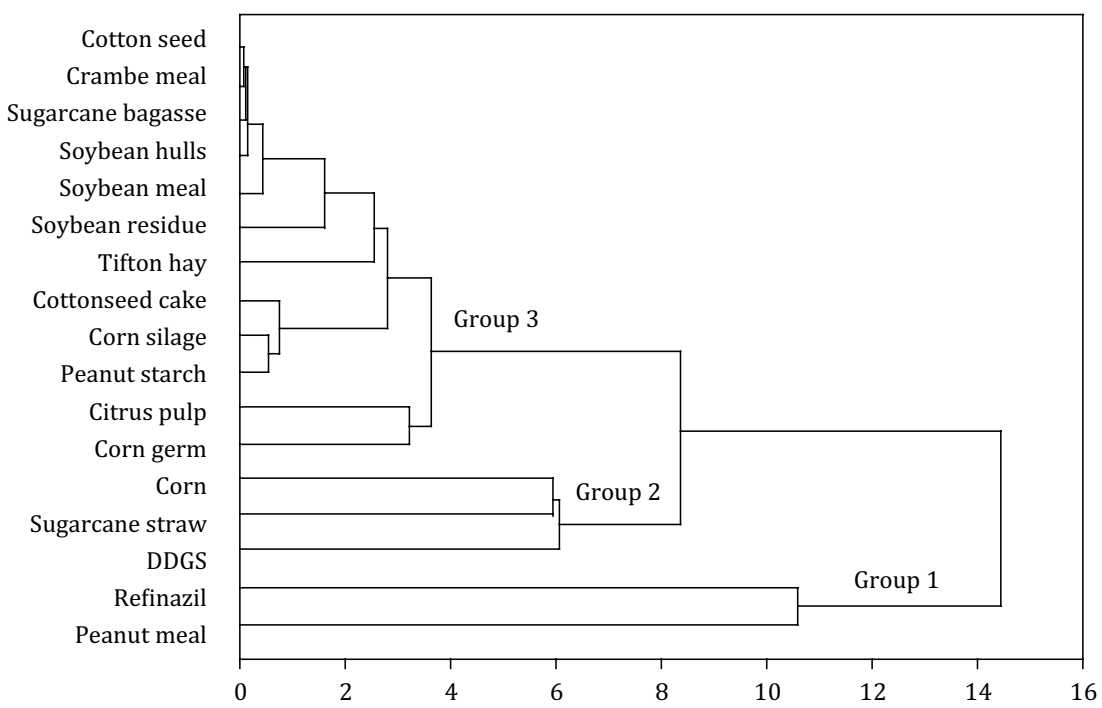

B

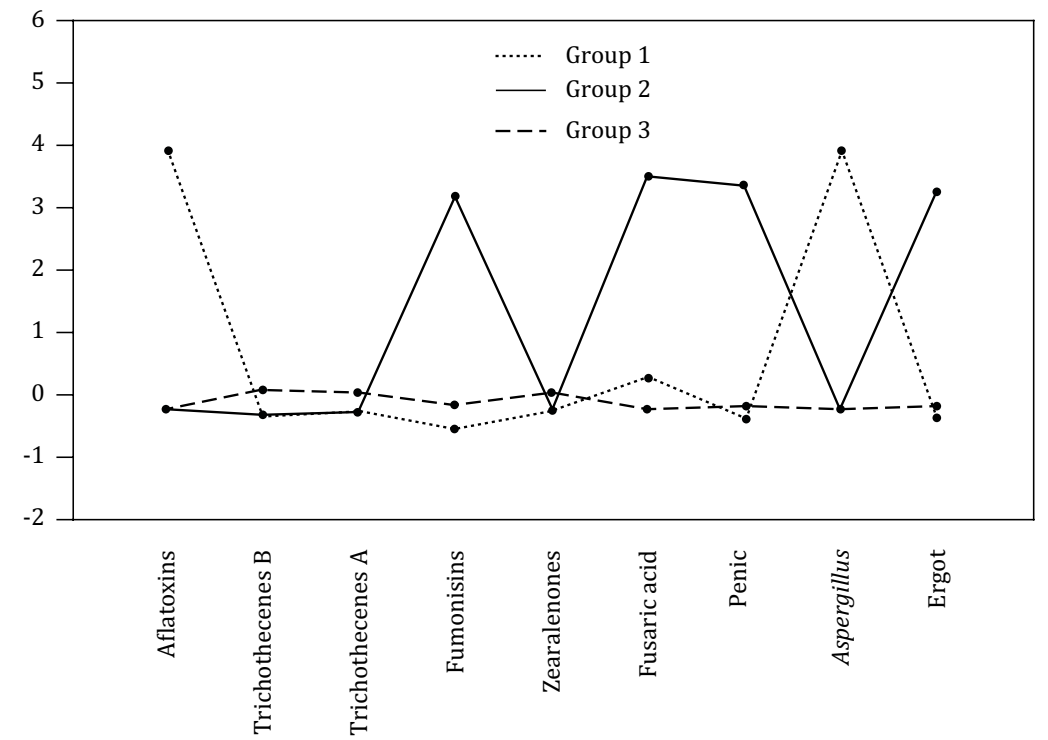

A: Group 1: most contaminated ingredients; Group 2: intermediate contaminated ingredients; Group 3: less contaminated ingredients.

B: aflatoxins: B1+B2+G1+G2; trichothecenes B = DON; trichothecenes A = toxin T-2 + HT-2; fumonisins = B1+B2; penic = patulin + penicillic acid + roquefortine $\mathrm{C}+$ mycophenolic acid + wortmannin; Aspergillus = gliotoxin + sterigmatocystin + verruculogen.

Figure 6 - Dendrogram of the cluster analysis by the hierarchical method and non-hierarchical method of groups profile 1, 2, and 3 constructed by the K-means algorithm of the ingredients from the ten most contaminated diets.

contaminated diets can cause lower intake, the variable that most influences performance (Diaz et al., 2000), besides affecting metabolic organs such as liver and kidneys (Fink-Gremmels, 2008).

Trichothecenes A and B are also produced by Fusarium species, and they are present in corn and forages (Tiemann and Danicke, 2007), widely used in TMR analyzed in this survey. These toxins are not very toxic for ruminants (Upadhaya et al., 2010). However, Danicke and Brezina (2013) reported that ruminants ingesting feed contaminated by DON present mycotoxin biotransformation and excretion in fluids such as blood and milk, thus classifying this mycotoxin as a risk to human health.

Fusaric acid also can be present in cereals and forage and was present in almost all TMR samples. Moreover, this toxin increases the toxicity of trichothecenes through a synergistic mechanism (Yiannikouris and Jouany, 2002). The synergism is common because mycotoxins are seldom found in isolation, and when multiple mycotoxins are consumed, they may have strong interactions that increase 
the risk to animal performance and health. As a result, the animal may have a stronger response than what would be expected if it consumed only a single mycotoxin.

Other mycotoxins, including aflatoxins, ergot, and mycotoxins produced by Penicillium were found. Aflatoxins are produced by Aspergillus flavus and Aspergillus parasiticus (Milićević et al., 2010). Peanut is a substrate that is most commonly contaminated by aflatoxin because it is one of the most susceptible foods to contamination by fungi that produce this toxin (Escobar and Regueiro, 2002). Moreover, although aflatoxin was present in only $6.7 \%$ of the TMR samples, it is very important for animal health (Battacone et al., 2012), because it is hepatotoxic, carcinogenic, and immunosuppressive (Williams et al., 2004), besides not being metabolized in the rumen, seriously affecting ruminants.

Ergot and mycotoxins produced by Penicillium can also be dangerous for ruminants. According to Coufal-Majewski et al. (2016), ergot alkaloids are produced by a group of fungi of the genus Claviceps and frequently found in cereal grains. When ingested by ruminants, this toxin can decrease feed intake, elevate body temperature, lead to excessive salivation, increase respiration rate, and decrease peripheral circulation (Merrill et al., 2007). Mycotoxins produced by Penicillium are mostly found in materials stored in bad conditions, such as silages and hays, and can reduce appetite, impact nutrient efficiency, and increase abomasal ulcers, laminitis, gastroenteritis, and paralysis (Gallo et al., 2015).

These toxins are notalways present in materials with obvious fungal growth, because the microorganisms may produce mycotoxins only if they suffer some type of stress (Bryden, 2012). This fact occurred in this study, because diets with high mycotoxin contamination did not present apparent fungi, and diets with apparent fungi had low or moderate contamination.

When the general data about feedlots and contamination levels of the samples were contrasted, it was observed that the contamination had no relationship with animal performance. The mean ADG of animals in the feedlots with high- or moderate-risk diets was $1.56 \mathrm{~kg} \mathrm{day}^{-1}$, whereas ADG of animals in feedlots with low-risk diets was $1.52 \mathrm{~kg} \mathrm{day}^{-1}$. The animals in feedlots with the highest ADG (1.85 kg day $\left.^{-1}\right)$ consumed moderate-risk diets, whereas animals in feedlots with the lowest ADG $\left(0.70 \mathrm{~kg} \mathrm{day}^{-1}\right)$, consumed a low-risk diet. This difference can be explained probably because of the variability of the genetic potential, animal management, and different diets. Studies to confirm the impact of mycotoxins on beef cattle performance need to be performed.

An important issue in this study related to what was stated above is the real risk of each mycotoxin in the feed. The concentration of each mycotoxin does not always demonstrate the real risk of the sample, since some mycotoxins are present in small concentrations, but may pose high risks to ruminants, or they may be present in high concentrations and pose low risk. Besides, the combination of different mycotoxins could be more dangerous than one single mycotoxin (Yiannikouris and Jouany, 2002).

In this way, besides identifying which mycotoxins were present in TMR and in which levels, it is also important to estimate the risks associated with the presence of different types and concentrations of mycotoxins. It was possible to estimate the equivalent risk of the feed through REQ, created by Yiannikouris (2015) based on the concepts of chemistry, which generates a real risk of the mycotoxin. The risk assessment calculates a REQ expressed in ppb of AFB1-equivalent, which computes a multi-contamination complex situation pertaining to feedstuffs into one single value (Yiannikouris, 2015). According to Yiannikouris (2015), the REQ, expressed as $\mu \mathrm{g} \mathrm{kg}^{-1}$ of AFB1- equivalent, can be classified, and the range between 0 to $50 \mu \mathrm{g} \mathrm{kg}^{-1}$ is considered low, 51 to $100 \mu \mathrm{g} \mathrm{kg}^{-1}$ is considered intermediate, and above $100 \mu \mathrm{g} \mathrm{kg}^{-1}$ is considered high for beef cattle. In this study, the maximum REQ found in TMR used in the feedlots evaluated was $230 \mu \mathrm{g} \mathrm{kg}^{-1}$, and the minimum REQ was $1 \mu \mathrm{g} \mathrm{kg}^{-1}$ AFB1-equivalent.

Besides, through the detection of multiple mycotoxins, it is possible to estimate the risk of all mycotoxins together (Yiannikouris and Jouany, 2002). Principal components showed part of this combination, since while aflatoxin is the most aggressive single mycotoxin, REQ is along with the other mycotoxins, probably because the combination of mycotoxins and their high concentrations could be more dangerous than aflatoxin by itself.

R. Bras. Zootec., 48:e20190079, 2019 
Therefore, these data demonstrated that it is important to consider the combined occurrence of different types of mycotoxins in ingredients and TMR samples. However, this is often neglected in other analytical approaches. Co-occurrences are important, since mycotoxins could have an additive effect, potentially further increasing their negative impact on the animal.

Another important issue to observe about mycotoxin contamination is that contamination by fungi is environmentally dependent, as these microorganisms thrive in more humid and high-temperature environments. Furthermore, the production of mycotoxins depends on environmental factors that can cause fungi stress, allowing them to produce toxins. In this sense, aflatoxin contamination occurs most often in the southern United States (Chaytor et al., 2011).

The Mato Grosso do Sul state in Brazil is characterized by a tropical climate, high temperature, wet in summer, and dry and cold winter. High temperatures and humidity can provide a condition for the great development of fungi, and dry and cold winter can cause some stress, which encourages mycotoxin production. Probably because of these factors, that state presented the greatest contaminations in TMR samples.

After all analyses of TMR samples, it was possible to further deepen the research into the diets through the analyses performed in the ingredients used in the TMR composition. Through this, we observe that from all ingredients, the most found roughage source was corn silage, and the most found concentrate sources were corn and cottonseed. These ingredients are very common in Brazilian feedlots. In a survey conducted by Millen et al. (2009) about management practices and nutritional recommendations used by feedlot nutritionists in Brazil, they observed that corn silage was used by $28.5 \%$ of the respondents as roughage source. They also observed that corn is the primary source of grain, while cottonseed was the primary byproduct used in feedlot diets.

Through the results of ingredient contamination from the ten most contaminated diets, it was possible to observe more specifically which ingredient was responsible for TMR contaminations and which mycotoxin stands out in each source. As aflatoxin is more dangerous for beef cattle, the ingredient that showed high concentrations of this mycotoxin, peanut meal, presented the highest REQ as well.

Aflatoxin is commonly found in peanut samples. In a study conducted by Escobar and Regueiro (2002), aflatoxin was found in $40.4 \%$ of peanuts analyzed. The occurrence of aflatoxins is higher in peanuts because it is the preferred product for the fungi that produce this toxin, and there are also delays and rains in the post-harvest drying period. Another form of contamination is when the peanut is stored under high humidity (Mupunga et al., 2017).

In addition to peanut, aflatoxin can be found in many other products widely used in Brazil, such as corn and oilseeds (Danicke and Brezina, 2013). These ingredients presented considerable contamination with high REQ such as corn and its byproducts (refinazil, DDGS) and soybean and soybean residues. However, only peanut and corn DDGS presented aflatoxin contamination.

Sugarcane straw also presents high REQ values; this contamination was due to trichothecenes $B$, trichothecenes A, and fusaric acid. Probably, these contaminations occurred because this material is the sugarcane residue that stays in the field after the harvest and is more subject to contamination.

The cluster analysis of all contaminated ingredients allowed the construction of a dendrogram resulting from hierarchical grouping analysis. In the dendrogram, it is possible to observe the formation of three groups: group 1 was characterized by the most contaminated ingredients; group 2, by mediumcontaminated ingredients; and group 3, by less contaminated ingredients.

Through the results of the cluster analysis by the non-hierarchical method, it was possible to observe the formation of three different groups. Group 1 had high contamination of aflatoxin and other mycotoxins produced by Aspergillus; group 2 had high contamination of fumonisin, fusaric acid, mycotoxins produced by Penicillium, and ergot; and group 3 had low contamination of all mycotoxins.

The clustering factors found in these analyses were the level of ingredient contamination. However, what was interesting is that the majority of mycotoxins of the same group are produced by the same 
fungal genus, e.g, in group 1, the mycotoxins produced by fungi of genus Aspergillus. In group 2, we observed fumonisin and fusaric acid, which are produced by genus Fusarium, although there is also the presence of ergot mycotoxins produced by Penicillium. Group 3 presents low contaminated samples for all mycotoxins.

In this way, what can be defined through these analyses is that the groups characterize the different ingredients, since each ingredient has a higher concentration of each mycotoxin. For example, corn and its byproducts with high concentrations of fumonisin and fusaric acid, while feeds such as peanuts have high concentrations of aflatoxin and mycotoxins by Aspergillus.

\section{Conclusions}

The survey results indicate that mycotoxins are a serious concern, evidencing that $100 \%$ of TMR in a feedlot is contaminated in Brazil. Fumonisins, trichothecenes A, trichothecenes B, fusaric acid, aflatoxins, and ergot are the mycotoxins present in TMR of feedlots. Mycotoxin concentrations have a distinct pattern among ingredients, TMR, and feedlots (local). Moreover, fumonisins are the mycotoxins found most frequently and at highest concentrations in TMR offered in Brazilian feedlots. Peanut meal is the most contaminated ingredient and is more aggressive for beef cattle. Besides, the greatest risk of contamination is in the combination of different mycotoxins instead of an isolated mycotoxin. Consequently, some strategies should be investigated to decrease or minimize the risk of mycotoxin contamination if TMR for beef cattle.

\section{Conflicts of Interest}

The authors declare no conflict of interest.

\section{Author Contributions}

Conceptualization: F.D. Resende and G.R. Siqueira. Data curation: L. Custódio. Formal analysis: L. Custódio. Funding acquisition: A. Yiannikouris, V. Holder, J. Pettigrew and L. Kuritza. Investigation: L. Custódio. Methodology: L. Custódio and G.R. Siqueira. Project administration: L. Custódio and G.R. Siqueira. Resources: A. Yiannikouris, V. Holder, J. Pettigrew and L. Kuritza. Software: L. Custódio and L.F. Prados. Supervision: V. Holder, J. Pettigrew, L. Kuritza, F.D. Resende and G.R. Siqueira. Writing-original draft: L. Custódio, L.F. Prados, A. Yiannikouris, J. Pettigrew and G.R. Siqueira. Writing-review \& editing: L. Custódio, L.F. Prados, A. Yiannikouris, J. Pettigrew and G.R. Siqueira.

\section{Acknowledgments}

The authors acknowledge the support of Fundação de Amparo à Pesquisa do Estado de São Paulo (FAPESP) for the scholarship granted to the first author (2015/21416-6) and for the PDIP grant (2017/50339-5). We thank Conselho Nacional de Desenvolvimento Científico e Tecnológico (CNPq) and FAPESP (2018/20176-0) for the scholarship granted to the second author. We also thank Alltech for supporting the analysis and language correction.

\section{References}

ANUALPEC. 2015. Anuário da pecuária brasileira. Informa Economics FNP, São Paulo.

Aslam, N.; Tipu, M. Y.; Ishaq, M.; Cowling, A.; McGill, D.; Warriach, H. M. and Wynn, P. 2016. Higher levels of aflatoxin M $_{1}$ contamination and poorer composition of milk supplied by informal milk marketing chains in Pakistan. Toxins 8:347. https://doi.org/10.3390/toxins8120347

Battacone, G.; Nudda, A.; Rassu, S. P. G.; Decandia, M. and Pulina, G. 2012. Excretion pattern of aflatoxin $\mathrm{M}_{1}$ in milk of goats fed a single dose of aflatoxin $B_{1}$. Journal of Dairy Science 95:2656-2661. https://doi.org/10.3168/jds.2011-5003 
Bryden, W. L. 2012. Mycotoxin contamination of the feed supply chain: implications for animal productivity and feed security. Animal Feed Science and Technology 173:134-158. https://doi.org/10.1016/j.anifeedsci.2011.12.014

Chaytor, A. C.; Hansen, J. A.; Heugten, E. V.; See, M. T. and Kim, S. W. 2011. Occurrence and decontamination of mycotoxins in swine feed. Asian-Australasian Journal of Animal Sciences 24:723-738. https://doi.org/10.5713/ajas.2011.10358

Coufal-Majewski, S.; Stanford, K.; McAllister, T.; Blakley, B.; McKinnon, J.; Chaves, A. V. and Wang, Y. 2016. Impacts of cereal ergot in food animal production. Frontiers in Veterinary Science 3:15. https://doi.org/10.3389/fvets.2016.00015

Danicke, S. and Brezina, U. 2013. Kinetics and metabolism of the Fusarium toxin deoxynivalenol in farm animals: consequences for diagnosis of exposure and intoxication and carry over. Food and Chemical Toxicology 60:58-75. https://doi.org/10.1016/j.fct.2013.07.017

Diaz, D. E.; Hopkins, B. A.; Leonard, L. M.; Hagler, W. M. and Whitlow, L. W. 2000. Effect of fumonisin on lactating dairy cattle. Journal of Dairy Science 83:1171.

Escobar, A. and Regueiro, O. S. 2002. Determination of aflatoxin B1 in food and feedstuffs in Cuba (1990 through 1996) using an immunoenzymatic reagent kit (Aflacen). Journal of Food Protection 65:219-221. https://doi.org/10.4315/0362028X-65.1.219

Fink-Gremmels, J. 2008. Mycotoxins in cattle feeds and carry-over to dairy milk: A review. Food Additives \& Contaminants 25:172-180. https://doi.org/10.1080/02652030701823142

Gallo, A.; Giuberti, G.; Frisvad, J. C.; Bertuzzi, T. and Nielsen, K. F. 2015. Review on mycotoxin issues in ruminants: occurrence in forages, effects of mycotoxin ingestion on health status and animal performance and practical strategies to counteract their negative effects. Toxins 7:3057-3111. https://doi.org/10.3390/toxins7083057

Merrill, M. L.; Bohnert, D. W.; Harmon, D. L.; Craig, A. M. and Schrick, F. N. 2007. The ability of a yeast-derived cell wall preparation to minimize the toxic effects of high-ergot alkaloid tall fescue straw in beef cattle. Journal of Animal Science 85:2596-2605. https://doi.org/10.2527/jas.2007-0075

Milićević, D. R.; Škrinjar, M. and Baltić, T. 2010. Real and perceived risks for mycotoxin contamination in foods and feeds: challenges for food safety control. Toxins 2:572-592. https://doi.org/10.3390/toxins2040572

Millen, D. D.; Pacheco, R. D. L.; Arrigoni, M. D. B.; Galyean, M. L. and Vasconcelos, J. T. 2009. A snapshot of management practices and nutritional recommendations used by feedlot nutritionists in Brazil. Journal of Animal Science 87:3427-3439. https://doi.org/10.2527/jas.2009-1880

Mupunga, I.; Mngqawa, P. and Katerere, D. R. 2017. Peanuts, aflatoxins and undernutrition in children in Sub-Saharan Africa. Nutrients 9:1287. https://doi.org/10.3390/nu9121287

Tiemann, U. and Danicke, S. 2007. In vivo and in vitro effects of the mycotoxins zearalenone and deoxynivalenol on different non-reproductive and reproductive organs in female pigs: A review. Food Additives \& Contaminants 24:306-314. https://doi.org/10.1080/02652030601053626

Tola, M. and Kebede, B. 2016. Occurrence, importance and control of mycotoxins: A review. Cogent Food \& Agriculture 2:1191103. https://doi.org/10.1080/23311932.2016.1191103

Upadhaya, S. D.; Park, M. A. and Ha, J. K. 2010. Mycotoxins and their biotransformation in the rumen: a review. Asian-Australasian Journal of Animal Sciences 23:1250-1260. https://doi.org/10.5713/ajas.2010.r.06

Vasconcelos, J. T. and Galyean, M. L. 2007. Nutritional recommendations of feedlot consulting nutritionists: the 2007 Texas Tech University survey. Journal of Animal Science 85:2772-2781. https://doi.org/10.2527/jas.2007-0261

Williams, J. H.; Phillips, T. D.; Jolly, P. E.; Stiles, J. K.; Jolly, C. M. and Aggarwal, D. 2004. Human aflatoxicosis in developing countries: a review of toxicology, exposure, potential health consequences, and interventions. American Journal of Clinical Nutrition 80:1106-1122. https://doi.org/10.1093/ajcn/80.5.1106

Yiannikouris, A. and Jouany, J. P. 2002. Mycotoxins in feeds and their fate in animals: a Review. Animal Research 51:81-99. https://doi.org/10.1051/animres:2002012

Yiannikouris, A. 2015. Holistic approach for the identification, risk assessment and mitigation of mycotoxins' impact in ruminant. Available at: <https://asas.confex.com/asas/mw15/webprogram/Paper11802.html>. Accessed on: Mar. 17, 2015.

Zhang, Y. and Caupert, J. 2012. Survey of mycotoxins in U.S. distiller's dried grains with solubles from 2009 to 2011. Journal of Agricultural Food Chemistry 60:539-543. https://doi.org/10.1021/jf203429f 